\title{
Prevalence of the polymorphic option C521T of the DRD4 gene at the attention defecit hyperactivity syndrome in children
}

\section{Saidkhodjaeva Saida}

Tashkent Pediatric medical institute, Uzbekistan

Email address:

doctor-saida1986@mail.ru (Saidkhodjaeva Saida)

\section{To cite this article:}

Saidkhodjaeva Saida. Prevalence of the polymorphic option C521T of the DRD4 gene at the attention attention dynamics with hyperactivity in children. Journal of research in health science. Vol. 2, No. 2, 2017, pp. 22-29. DOI 10.26739/2523-1243

$$
\text { http://dx.doi.org/10.26739/2523-1243/-2017-2-2-5 }
$$

Abstract: in this article, we analyzed molecular-genetic research of marker genes as the formation of ADHD and was studied the role of polymorphism rs 1800955 of DRD4 gene. Given the genetic characteristics of each population and ethnic groups, the study and development of the genetic nature of ADHD in children in Uzbekistan is promising.

Keywords: children, genetic, attention deficit huperactivity disorder.

\section{Распространенность полиморфного варианта C521T гена DRD4 при синдроме дефицита внимания с гиперактивностью у детей}

Анотация: в этой статье проанализировали молекулярно-генетическое исследование маркерных генов как основу формирования СДВГ и изучили роль полиморфизма rs 1800955 гена DRD4. Учитывая генетические характеристики каждой популяции и этнических групп, изучение и развитие генетической природы СДВГ у детей в Узбекистане является многообещающим.

Ключевое слова: дети, генетика, синдром дефицита внимания с гиперактивностью. 
Синдром дефицита внимания с гиперактивностью (attention deficit hyperactivity disorder) [1], именуемый также гиперкинетическим расстройством [2], наблюдается у детей в возрасте от 3 до 15 лет, но наиболее часто проявляет себя в дошкольном и младшем школьном возрасте. Данное расстройство является одной из форм минимальных мозговых дисфункций у детей. Оно характеризуется патологически низкими показателями внимания, памяти, слабостью мыслительных процессов в целом при нормальном уровне интеллекта. Произвольная регуляция развита слабо, работоспособность на занятиях низкая, утомляемость повышена. Также отмечаются отклонения в поведении: двигательная расторможенность, повышенная импульсивность и возбудимость, тревожность, реакции негативизма, агрессивность. При начале систематического обучения возникают трудности в освоении письма, чтения и счета. На фоне учебных трудностей и, нередко, отставании в развитии социальных навыков возникает школьная дезадаптация и различные невротические расстройства. Клинические проявления синдрома дефицита внимания с гиперактивностью (СДВГ) детально описаны в большом числе монографий и обзоров [3-6].

Высокая распространенность (3$17 \%)$, сохранение симптомов в подростковом и взрослом возрасте, отсутствие высокоэффективных методов лечения и коррекции обуславливают актуальность изучения механизмов данного расстройства [35]. На сегодняшний день общеприняты четыре патогенетические концепции СДВГ: нейропсихологическая нарушения самоконтроля и регуляции, нейрофизиологическая - нарушения в префронтальной коре и стриатуме, биохимическая - отклонения в развитии катехоламинэргических систем, генетическая - нарушения экспрессии генов дофаминового рецептора (DRD4) и дофаминового транспортера (DAT1) [4, 5].

Ген рецептора дофамина 4-го типа (DRD4), располагающийся на коротком плече хромосомы 11 (11p15.5), кодирует один из пяти протеи-нов-рецепторов дофамина. Рецептор D4, открытый относительно недавно, экспрессируется в коре головного мозга, тканях миндалины (миндалевидного тела), гипоталамусе, гиппокампе, гипофизе и базальных ганглиях, распространен в префронтальной коре и стриатуме [Congdon, Canli, 2008 Congdon E., Canli T. A neurogenetic approach to impulsivity. J. Pers. 2008. 76(6): 1447-84.]. Биологической функцией синтезированных белков-рецепторов DRD4 является распознавание этого нейромедиатора на поверхности постсинаптической клетки.

По данным некоторых авторов, имеется связь данного рецептора с формированием синдрома дефицита внимания с гиперактивностью (СДВГ) у детей [Thapar A. et al. Advances in genetic findings on attention deficit hyperactivity disorder // Psychological medicine. - 2007. - T. 37. № 12. - C. 1681-1692]. Ген, ответственного за синтез рецептора DRD4 отличается необычайно высокой степенью, так называемого, полиморфизма, что делает его весьма перспективным

объектом 
Saidkhodjaeva Saida. Prevalence of the polymorphic option C521T of the DRD4 gene at the attention attention dynamics with hyperactivity in children

м о ле к у л я р н о - ге н е т и ч е с и х исследований. Эти полиморфизмы расположены в регулирующих, кодирующих и интронных позициях гена. Полиморфизм rs1800955, кодирующая часть гена DRD4, расположен в промоторной области гена. Данный полиморфизм представляет заменой цитозина (аллель С) на тимин (аллель Т) в позиции - 521 (С521Т или 521C/Т). По данным Ebstein, 2006, функционально-неблагоприятный "521T" аллель приводит к снижению эффективности транскрипции гена на $40 \%$, а у гомозигот С/C более высокие оценки по шкале поиска новизны по TPQ [Ebstein R.P. The molecular genetic architecture of human personality: beyond selfreport questionnaires. Mol. Psychiatry. 2006. 11(5): 427-45]. Кроме того, Голимбет и др., 2005, выявили связь между снижением социальной активности с преимущественно с носительством аллеля "521T" [Голимбет В.Е., Гриценко И.К., Алфимова М.В., Эпштейн Р.П. Полиморфные маркеры промоторного участка гена дофаминового рецептора D4 и черты темперамента у психически здоровых людей из русской популяции. Генетика. 2005. 41(7): 966-972.]. Гомозиготы по данному аллелю эффективнее отслеживают совершение ошибок, что на поведенческом уровне проявляется в большем постошибочном замедлении поведения [Krä mer U.M., Cunillera T., Càmara E., Marco-Pallarés J., Cucurell D., Nager W., Bauer P., Schüle R., Schöls L., Rodriguez The impact of catechol-O-methyltransferase and dopamine D4 receptor genotypes on neurophysiological markers of performance monitoring. The J. Neuroscience. 2007. 27(51): 14190-14198].

В настоящее время исследователи ведущих научных Центров развитых стран мира уделяют значительное внимание выявлению геновкандидатов, участвующих в сложных психических, поведенческих расстройствах, в том числе и в формировании СДВГ у детей.

Однако, число работ, посвященных именно взаимосвязи формирования СДВГ и изменениям на генном уровне, крайне невелико и пока поиск ассоциативной связи дает противоречивые результаты [Douglas, F. Levinsonet et al. Genetics of Recurrent Early-Onset Major Depression (GenRED): Significant Linkage on Chromosome 15q25- q26 After Fine Mapping With Single Nucleotide Polymorphism Markers Am J Psychiatry. - 2007. - V. 164].

Цель работы. Учитывая генетические особенности каждой популяции и этнических групп, представляется перспективным изучение связи между полиморфизмом rs1800955 гена DRD4 и развитием СДВГ у детей в Узбекистане.

Материалы и методы исследования: был изучен полиморфизм rs1800955 гена DRD4, рассматриваемый в качестве маркера формирования СДВГ в группе пациентов с данным диагнозом и в контрольной выборке. Распределение аллелей и генотипов данного полиморфизма в исследованных группах проверяли на соответствие РХВ с помощью точного теста Фишера и с использованием пакета статистических программ "GenePop". 
Результаты и их обсуждение. В исследованных группах распределение частот генотипов rs1800955 гена DRD4 и их соответствие популяционному равновесию РХВ проводилось раздельно. Результаты исследования представлены в таблицах 1, 2, 3 и 4.

\section{Таблица 1}

Частота распределение аллелей и генотипов полиморфизма $\mathrm{C} / \mathrm{T}$ гена DRD4 в группах пациентов

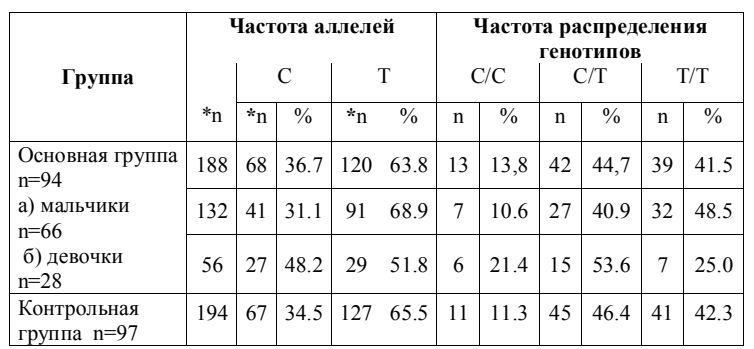

\section{Примечание:}

1. *n -число обследованных хромосом

2. n - число обследованных лиц

Как видно из таблиц 1 и 2, в группе пациентов с СДВГ выявлено, что фактическая частота гомозиготного генотипа C/C неожиданно низка и статистически незначимо повышена, по сравнению с теоретическим $\left(\mathrm{H}_{\mathrm{obs}}\right.$ $=0.14 \%$ и $\mathrm{H}_{\mathrm{exp}}=0.13 \%$, соответственно, $\left.\mathrm{X}^{2}=0.04 ; \mathrm{p}>0,05\right)$. Наблюдаемое количество гетерозигот С/Т наоборот, недостоверно ниже, чем ожидаемое $\left(\mathrm{H}_{\mathrm{obs}}=0.45 \%\right.$ и $\quad \mathrm{H}_{\text {exp }}=0.46 \%$ соответственно, $\left.\mathrm{X}^{2}=0,045 ; \mathrm{p}>0,05\right)$. Показатель относительного отклонения ожидаемой гетерозиготности от наблюдаемой оказался отрицательным (дефицит гетерозигот), т.е., $\mathrm{D}=-0.02$ (табл. 1). Однако, подобный умеренный недостаток С/T гетерозигот компенсируется избытком С/C гомозигот. Наблюдаемое распре- деление частот неблагоприятного генотипа $\mathrm{T} / \mathrm{T}$ также соответствовало равновесию Харди-Вайнберга (РХВ) $\left(\mathrm{H}_{\mathrm{obs}}=0.41 \%\right.$ и $\left.\mathrm{H}_{\mathrm{exp}}=0.41 \%\right)$, о чем свидетельствовало значение $\mathrm{X}^{2}=0,01$ и $\mathrm{p}>0,05$ (табл. 2).

\section{Таблица 2}

Распределение частот аллелей и генотипов полиморфизма $\mathrm{C} / \mathrm{T}$ гена DRD4 и тест Харди-Вайнберга в группе пациентов

\begin{tabular}{|c|c|c|c|c|c|c|c|}
\hline \multirow{2}{*}{ SNP } & \multicolumn{2}{|c|}{ Локализация } & \multirow{2}{*}{$\begin{array}{c}\text { Генотипи } \\
\text { ческие } \\
\text { варианты }\end{array}$} & \multicolumn{2}{|c|}{ Частота генотипов } & \multicolumn{2}{|c|}{$\begin{array}{c}\text { Различия по } \\
\text { РХВ }\end{array}$} \\
\hline & $\begin{array}{c}\text { хромосом } \\
\text { ное }\end{array}$ & генное & & $\begin{array}{c}\text { Наблюда } \\
\text { емое }\end{array}$ & \begin{tabular}{|c|} 
ожидае \\
мое
\end{tabular} & $\chi^{2}$ & $P$ \\
\hline \multirow{4}{*}{$\begin{array}{c}\text { rs } \\
1800955\end{array}$} & \multirow{4}{*}{$11, \mathrm{p} 15.5$} & \multirow{4}{*}{636784} & $\mathrm{C} / \mathrm{C}$ & 0.14 & 0.13 & 0,040 & \multirow[b]{4}{*}{0.75} \\
\hline & & & $\mathrm{C} / \mathrm{T}$ & 0.45 & 0.46 & 0,045 & \\
\hline & & & $T / T$ & 0.41 & 0.41 & 0,013 & \\
\hline & & & Всего & 1,00 & 1,00 & 0,1 & \\
\hline
\end{tabular}

В таблице 3 продемонстрированы результаты сравнительных данных генетической структуры полиморфизма rs1800955 гена DRD4 в популяционной выборке.

Таблица 3

Распределение частот аллелей и генотипов полиморфизма $\mathrm{C} / \mathrm{T}$ гена DRD4 и тест Харди-Вайнберга в популяционной выборке

\begin{tabular}{|c|c|c|c|c|c|c|c|}
\hline \multirow{2}{*}{ SNP } & \multicolumn{2}{|c|}{ Локализация } & \multirow{2}{*}{$\begin{array}{c}\text { Генотипич } \\
\text { еские } \\
\text { варианты }\end{array}$} & \multicolumn{2}{|c|}{$\begin{array}{c}\text { Частота } \\
\text { генотипов }\end{array}$} & \multicolumn{2}{|c|}{$\begin{array}{c}\text { Различия } \\
\text { по РХВ }\end{array}$} \\
\hline & $\begin{array}{c}\text { хромосом } \\
\text { ное }\end{array}$ & генное & & \begin{tabular}{|c|}
$\begin{array}{c}\text { Наблюд } \\
\text { аемое }\end{array}$ \\
\end{tabular} & $\begin{array}{c}\text { Ожидае } \\
\text { мое }\end{array}$ & $\chi^{2}$ & $\mathrm{P}$ \\
\hline \multirow{4}{*}{ rs 1800955} & \multirow{4}{*}{$11, \mathrm{p} 15.5$} & \multirow{4}{*}{636784} & $\mathrm{C} / \mathrm{C}$ & 0.11 & 0.12 & 0,03 & \multirow[b]{4}{*}{0.8} \\
\hline & & & $\mathrm{C} / \mathrm{T}$ & 0.46 & 0.45 & 0,03 & \\
\hline & & & $\mathrm{T} / \mathrm{T}$ & 0.42 & 0.43 & 0,01 & \\
\hline & & & Всего & 1.0 & 1.0 & 0,06 & \\
\hline
\end{tabular}

В данной группе также зафиксированы всевозможные генотипы, а их частота распределения, соответствует РХВ свидетельствующему о правильности постановки, интерпретации ПЦР анализа и определению выборки группы контроля. Как и следовало ожидать и 
Saidkhodjaeva Saida. Prevalence of the polymorphic option C521T of the DRD4 gene at the attention attention dynamics with hyperactivity in children

в популяционной выборке дикий генотип С/С характеризовался низкой частотой и его частота согласуется с ожидаемыми (0.11 против 0.12 , соответственно; $\left.\mathrm{X}^{2}=0.03 ; \mathrm{P}>0.05\right)$.

Фактическое распределение гетерозиготного генотипа незначительно повышено, по сравнению с теоретическим $(0.46$ против 0.45 соответственно; $\mathrm{X}^{2}=0.03$; $\mathrm{P}>0.05$ ). Относительное отклонение наблюдаемой гетерозиготности от ожидаемой оказалось положительным, т.е., уровень наблюдаемой гетерозиготности был больше ожидаемого $(\mathrm{D}=+0.02$; умеренный избыток гетерозигот). Наблюдаемое распределение неблагоприятного генотипа T/T также недостоверно снижено по сравнению с теоретическим (0.43 против $0.42 ; \mathrm{X}^{2}=$ $0.01 ; \mathrm{P}>0.05$.).

\section{Относительное отклонение ожидаемой гетерозиготности от наблюдаемой полиморфизма C/T гена DRD4.}

Таблица 4

\begin{tabular}{|c|c|c|c|}
\hline Группы & $\begin{array}{c}\text { Наблюдаемая } \\
\text { гетерозиготность }\end{array}$ & $\begin{array}{c}\text { Ожидаемая } \\
\text { гетерозиготность }\end{array}$ & $\mathbf{D}$ * \\
\hline Основная группа & 0.45 & 0.46 & -0.02 \\
\hline Контрольная группа & 0.46 & 0.45 & +0.02 \\
\hline
\end{tabular}

Таким образом, в исследованных группах пациентов и контроля наблюдаемое распределение частот генотипов по данному полиморфизму не отклонялось от РXВ, т.е. соответствовало рассчитанной ожидаемой величине $\left(\chi^{2}<3.8 ; \mathrm{P}>0.05\right)$. С учетом достаточного объема выборки пациентов и контроля (94 и 97 соответственно) можно говорить о действительном отсутствии отклонений от РXВ. Значимое соответствие PXВ указывает на однородность исследованных групп пациентов с СДВГ и контроля.

Oсобое внимание обращает неожиданно выявленная низкая частота дикого генотипа C/C среди пациентов и группы контроля 0.14 и $0.11(14.0 \%$ и $11.0 \%)$ соответственно, что, возможно, свидетельствует об особенности генетической структуры нашего региона по данному локусу. Значение Нехр в этих группах составляло 0.45 и 0.46 соответственно, что свидетельствует о достаточно высоком уровне гетерозиготности и, соответственно, генетической изменчивости локуса rs1800955 гена DRD4 в нашей популяции. Гетерозиготность по определенным полиморфизмам является показателем высокой жизнеспособности и хорошей приспособляемости популяции к изменяющимся условиям среды.

Для выявления возможной ассоциации полиморфизма rs 1800955 гена DRD4 с формированием СДВГ был проведен сравнительный анализ частот генотипов и аллелей изученных генов между выборкой пациентов и контролем, а также между подгруппами мальчиков и девочек. Сравнительный анализ частот генотипов и аллелей полиморфизма rs1800955 гена DRD4 между группой пациентов с СДВГ и контрольной группой не выявил статистически достоверных различий. Как видно из таблицы 1 частоты генотипов C/C, C/ Т и Т/Т составили: $13.8 \%, 44.7 \%$ и $41.5 \%$ - в группе пациентов и $11.3 \%$, $46.4 \%$ и $42.3 \%$ - в группе контроля соответственно. Частоты аллелей $521 \mathrm{C}$ и $521 \mathrm{~T}$ составили: $36,7 \%$ и $63.8 \%$ - в основной группе и $34.5 \%$ и $65.5 \%$ - в группе контроля. 
При сравнении частот генотипов и аллелей полиморфизма rs1800955 гена DRD4 между подгруппами пациентов с СДВГ и контрольной группой также не были выявлены статистически значимые различия (табл. $5,6,7,8$ ). Частоты генотипов C/C, C/T и T/T в этих подгруппах составили: $10.6 \%$, $40.9 \%$ и $48.5 \%$ - для мальчиков, $21.4 \%$, $53.6 \%$ и $25.0 \%$ - для девочек и не отличались от таковых в контрольной группе и между собой. Частоты аллелей $521 \mathrm{C}$ и $521 \mathrm{~T}$ составили: $31.1 \%$ и $68.9 \%$ в подгруппе мальчиков и $48.2 \%$ и $51.8 \%$ в подгруппе девочек.

Во всех исследуемых группах аллель $521 \mathrm{~T}$ являлся преобладающим, его частота колебалась от $51.8 \%$ до $68.9 \%$ соответственно. При этом самым частым генотипом являлся генотип Т/ Т (от $25.0 \%$ до $48.5 \%$ ), а наиболее редким - генотип С/C (от $10.6 \%$ до $21.4 \%)$.

Необходимо подчеркнуть что, в подгруппе девочек, отмечалась тенденция к увеличению частоты встречаемости дикого аллеля 521С и снижение частоты встречаемости мутантного аллеля 521Т по сравнению c подгруппой мальчиков (48.2\% против $31.1 \%$ ) и популяционной выборкой (48.2\% против $34.5 \%)$. Однако, во всех случаях различия оказались статистически незначимыми $\left(\mathrm{X}^{2}<3.8 ; \mathrm{P}>0.05\right)$, но в то же время, близки к статистически значимому уровню. Соответственно у пациенток частота генотипа мутантного типа T/ Т снижена и близка к статистически значимому, по сравнению с подгруппой мальчиков $(25.0 \%$ против $48.5 \%)$ и группой контроля (25.0\% против 42.3\%).
Таблица 4

Частота распределение аллелей и генотипов полиморфизма $\mathrm{C} / \mathrm{T}$ гена DRD4 в группах пациентов

\begin{tabular}{|c|c|c|c|c|c|c|c|c|c|c|}
\hline \multirow{3}{*}{ Группа } & \multicolumn{5}{|c|}{ Частота аллелей } & \multicolumn{5}{|c|}{$\begin{array}{c}\text { Частота распределения } \\
\text { генотипов }\end{array}$} \\
\hline & \multirow[b]{2}{*}{$*_{\mathrm{n}}$} & \multicolumn{2}{|c|}{$\mathrm{C}$} & \multicolumn{2}{|c|}{$\mathrm{T}$} & \multicolumn{2}{|c|}{$\mathrm{C} / \mathrm{C}$} & \multicolumn{2}{|c|}{$\mathrm{C} / \mathrm{T}$} & $\mathrm{T} / \mathrm{T}$ \\
\hline & & ${ }^{*} \mathrm{n}$ & $\%$ & ${ }^{*} \mathrm{n}$ & $\%$ & $\mathrm{n}$ & $\%$ & $\mathrm{n}$ & $\%$ & $\%$ \\
\hline \multirow{3}{*}{$\begin{array}{l}\text { Основная группа } \\
\mathrm{n}=94 \\
\text { a) мальчики } \\
\mathrm{n}=66 \\
\text { б) девочки } \\
\mathrm{n}=28\end{array}$} & 188 & 68 & 36.7 & 120 & 63.8 & 13 & 13,8 & 42 & 44,7 & $39 \quad 41.5$ \\
\hline & 132 & 41 & 31.1 & 91 & 68.9 & 7 & 10.6 & 27 & 40.9 & $32 \quad 48.5$ \\
\hline & 56 & 27 & 48.2 & 29 & 51.8 & 6 & 21.4 & 15 & 53.6 & 25.0 \\
\hline $\begin{array}{l}\text { Контрольная } \\
\text { группа } \mathrm{n}=97\end{array}$ & 194 & 67 & 34.5 & 127 & 65.5 & 11 & 11.3 & 45 & 46.4 & $41 \quad 42.3$ \\
\hline
\end{tabular}

Примечание: *n -число обследованных хромосом

Таблица 5.

Различия в частоте встречаемости аллелей и генотипов полиморфизма

C/T гена DRD4 в основной и контрольной группах

\begin{tabular}{|c|c|c|c|}
\hline \multirow{2}{*}{$\begin{array}{l}\text { Аллели и } \\
\text { генотипы }\end{array}$} & \multicolumn{2}{|c|}{$\begin{array}{c}\text { Количество обследованных } \\
\text { аллелей и генотипов }\end{array}$} & \multirow{2}{*}{ Статистическое различие } \\
\hline & $\begin{array}{l}\text { Основная } \\
\text { группа }\end{array}$ & Контроль & \\
\hline Аллель C & 68 & 67 & \multirow{5}{*}{$\chi^{2}<3.8 ; P>0.05$} \\
\hline Аллель T & 120 & 127 & \\
\hline Генотип C/C & 13 & 11 & \\
\hline Генотип C/T & 42 & 45 & \\
\hline Генотип Т/T & 39 & 41 & \\
\hline
\end{tabular}

Примечание: *- различие статистически достоверное.

По частоте встречаемости генотипов также наблюдалось недостоверное увеличение частоты гетерозиготного генотипа С/T в подгруппе девочек (53.6\%), по сравнению с подгруппой мальчиков $(40.9 \%)$ и группой контроля (46.4\%) (табл. 6, 7, 8).

Таблица 6.

Различия в частоте встречаемости аллелей и генотипов полиморфизма

C/T гена DRD4 в подгруппе мальчиков и контрольной группе

\begin{tabular}{|c|c|c|c|}
\hline \multirow{2}{*}{$\begin{array}{l}\text { Аллели и } \\
\text { генотипы }\end{array}$} & \multicolumn{2}{|c|}{$\begin{array}{c}\text { Количество об́ледованных } \\
\text { аллелей и генотипов }\end{array}$} & \multirow{2}{*}{$\begin{array}{c}\text { Статистическое } \\
\text { различие }\end{array}$} \\
\hline & Мальчики & Контроль & \\
\hline Аллель C & 41 & 67 & \multirow{5}{*}{$\chi^{2}<3.8 ; \mathrm{P}>0.05$} \\
\hline Аллель T & 91 & 127 & \\
\hline Генотип $\mathrm{C} / \mathrm{C}$ & 7 & 11 & \\
\hline Генотип C/T & 27 & 45 & \\
\hline Генотип Т/Т & 32 & 41 & \\
\hline
\end{tabular}


Saidkhodjaeva Saida. Prevalence of the polymorphic option C521T of the DRD4 gene at the attention attention dynamics with hyperactivity in children

Таким образом, в результате проведенного анализа полиморфного варианта rs1800955 гена DRD4 установлено, что данный ДНК-локус самостоятельно не ассоциирован с формированием СДВГ. При этом, обнаружена выраженная тенденция к гендерным различиям в распределении частот аллелей и генотипов данного полиморфизма. Причиной тому, что в данном случае ассоциация была отмечена в предполагаемом направлении, но лишь на уровне тенденции мог являться ряд ограничений настоящего исследования.

\section{Таблица 7. \\ Различия в частоте встречаемости аллелей и генотипов полиморфизма C/T гена DRD4 в подгруппе девочек и контрольной группе}

\begin{tabular}{|c|c|c|c|}
\hline \multirow[t]{2}{*}{$\begin{array}{l}\text { Аллели и } \\
\text { генотипы }\end{array}$} & \multicolumn{2}{|c|}{$\begin{array}{c}\text { Количество } \\
\text { обследованных } \\
\text { аллелей и генотипов }\end{array}$} & \multirow[t]{2}{*}{ Статистическое различие } \\
\hline & Девочки & Контроль & \\
\hline Аллель C & 27 & 67 & $\chi^{2}=3.6 ; \mathrm{P}=0.06 ; \mathrm{OR}=1.8 ; 95 \%$ CI $0.96-$ \\
\hline Аллель T & 29 & 127 & 3.22 \\
\hline Генотип C/C & 6 & 11 & $\chi^{2}=1.9 ; \mathrm{P}=0.2 ; \mathrm{OR}=2.1 ; 95 \%$ CI $0.71-6.4$ \\
\hline Генотип C/T & 15 & 45 & $\begin{array}{l}\chi^{2}=0.4 ; \quad \mathrm{P}=0.5 ; \quad \mathrm{OR}=1.3 ; 95 \% \text { CI } 0.57- \\
3.09\end{array}$ \\
\hline Генотип Т/T & 7 & 41 & $\begin{array}{l}\chi^{2}=2.7 ; \mathrm{P}=0.09 ; \mathrm{OR}=0.4 ; 95 \% \text { CI } 0.17- \\
1.17\end{array}$ \\
\hline
\end{tabular}

К таким ограничениям следует отнести недостаточную численность выборки, связанную с еe относительно объемом в подгруппах, а также возможное влияние эффекта выборки условно-здоровых детей.

Таблица 8.

Различия в частоте встречаемости аллелей и генотипов полиморфизма

C/T гена DRD4 в подгруппах мальчиков и девочек

\begin{tabular}{|l|c|c|l|}
\hline \multirow{2}{*}{$\begin{array}{c}\text { Аллели и } \\
\text { генотипы }\end{array}$} & \multicolumn{2}{|c|}{$\begin{array}{c}\text { Количество } \\
\text { обследованных } \\
\text { аллелей и генотипов }\end{array}$} & \multirow{2}{*}{ Статистическое различие } \\
\cline { 2 - 3 } & Мальчики & Девочки & \\
\hline Аллель С & 41 & 27 & $\chi^{2}=5.0 ; \mathrm{P}=0.02 ;$ OR $=0.5 ; 95 \%$ CI $0.25-$ \\
\hline Аллель Т & 91 & 29 & 0.92 \\
\hline Генотип C/C & 7 & 6 & $\chi^{2}<3.8 ; \mathrm{P}>0.05$ \\
Генотип С/T & 27 & 15 & $\chi^{2}<3.8 ; \mathrm{P}>0.05$ \\
\hline Генотип Т/T & 32 & 7 & $\chi^{2}<3.8 ; \mathrm{P}>0.05$ \\
\hline
\end{tabular}

Считаем, что для окончательного прояснения данного обстоятельства требуется продолжение исследования в данном направлении, и проведение дополнительных исследований на расширенных выборках пациентов и групп контроля. Возможно, что при увеличении объема выборки, особенно подгруппы девочек эти различия окажутся статистически значимыми.

\section{Список использованной литературы:}

1. Мастюкова Е. М., Московкина А. Г. Основы генетики: Клинико- генетические основы коррекционной педагогики и специальной психологии. Учеб. пособие для студ. пед. высш. учеб. заведений / Под ред. В. И. Селиверстова, Б. П. Пузанова. - М.: Гуманит. изд. центр ВЛАДОС, 2001. - 368 c.

2. Albayrak O., Friedel S., Schimmelmann B.G. Genetic Aspects in Attention-deficit/Hyperactivity Disorder//J. of Neural Transmission. 2008. № 115. P. 305-315.

3. Arnsten Amy F. T. Toward a New Understanding of Attention-Deficit Hyperactivity Disorder Pathophysiology: An Important Role for Prefrontal Cortex Dysfunction // CNS Drugs, Supplement. 2009. Vol. 23. P. 33-41.

4. Curatolo P., Paloscia C., D'Agati E., Moavero R., Pasini A. The neurobiology of attention deficit / hyperactivity disorder / Paolo Curatolo, Claudio Paloscia, Elisa D'Agati, Romina Moavero, Augusto Pasini // European Journal of Paediatric Neurology. 2009. Vol. 13. № 4. P. 299-304.

5. Levitan R.D., MasellisM., LamR.W., etal. (2004). Childhood inattention and dysphoria and adult obesity associated with the dopamine D4 receptor gene in overeating women with seasonal affective disorder. 2004, 29, 179-186. 
Journal of research in health science. 2017; 2 (2): 22-29.

6. Congdon, Canli, 2008 Congdon E., Canli T. A neurogenetic approach to impulsivity. J. Pers. 2008. 76(6): 1447-84.

7. Thapar A. et al. Advances in genetic findings on attention deficit hyperactivity disorder // Psychological medicine. - 2007. - T. 37. - № 12. - C. 1681-1692

8. Ebstein R.P. The molecular genetic architecture of human personality: beyond selfreport questionnaires. Mol. Psychiatry. 2006. 11(5): 427-45

9. Голимбет В.Е., Гриценко И.К., Алфимова М.В., Эпштейн Р.П. Полиморфные маркеры промоторного участка гена дофаминового рецептора D4 и черты темперамента у психически здоровых людей из русской популяции. Генетика. 2005. 41(7): 966-972.

10. Kr?mer U.M., Cunillera T., C?mara E., Marco-Pallar?s J., Cucurell D., Nager W., Bauer P., Sch?le R., Sch?ls L., Rodriguez The impact of catechol-O-methyltransferase and dopamine D4 receptor genotypes on neurophysiological markers of performance monitoring. The J. Neuro-science. 2007. 27(51): 14190-14198

11. Douglas, F. Levinsonet et al. Genetics of Recurrent Early-Onset Major Depression (GenRED): Significant Linkage on Chromosome 15q25- q26 After Fine Mapping With Single Nucleotide Polymorphism Markers Am J Psychiatry. - 2007. - V. 164 